\title{
A FORMAÇÃO DOCENTE E AS (IN) COMPREENSÕES EPISTEMOLÓGICAS: REVELAÇÕES DO PNAIC
}

\author{
LA FORMACIÓN DOCENTE Y LAS (IN) COMPRENSIONES \\ PISTEMOLÓGICAS: REVELACIONES DEL PNAIC
}

THE TRAINING TEACHERS AND THE EPISTEMOLOGICAL UNDERSTANDINGS: REVELATIONS OF THE PNAIC

\author{
Claudecir dos SANTOS ${ }^{1}$ \\ Marciane MACIEL ${ }^{2}$
}

RESUMO: A partir de um estudo realizado no e com o Pacto Nacional pela Alfabetização na Idade Certa (PNAIC) em um município de Santa Catarina, o presente artigo problematiza algumas questões acerca das imbricações entre concepções epistemológicas, realidade da sala de aula e processos de alfabetização. Fundamentado na epistemologia de Thomas Kuhn, o artigo destaca que muitos professores desconhecem técnicas e métodos de formação pedagógica por conta de (in) compreensões epistemológicas não resolvidas durante sua formação inicial (primeira Licenciatura).

PALAVRAS-CHAVE: PNAIC. Epistemologia. Formação docente.

RESUMEN: A partir de un estudio realizado en el y con el Pacto Nacional por la Alfabetização en la Edad Correcta (PNAIC) en un municipio de Santa Catarina, el presente artículo problematiza algunas cuestiones acerca de las imbricações entre concepciones epistemológicas, realidad de la sala de clase y procesos de alfabetização. Fundamentado en la epistemologia de Thomas Kuhn, el artículo destaca que muchos profesores desconocen técnicas y métodos de formación pedagógica por cuenta de (in) comprensiones epistemológicas no resueltas durante su formación inicial (primera Licenciatura).

PALABRAS CLAVE: PNAIC. Epistemologia. Formación docente.

ABSTRACT: Based on a study carried out in and with the National Pact for Literacy in the Right Age (PNAIC) in a city in the state of Santa Catarina, the present article questions some issues about the imbrications between epistemological conceptions, classroom reality, and literacy processes. Based on the epistemology of Thomas Kuhn, the article

\footnotetext{
${ }^{1}$ Universidade Federal da Fronteira Sul (UFFS), Chapecó - SC - Brasil. Professor no curso de Ciências Sociais e no Mestrado em Educação. Doutor em Filosofia. ORCID: <https://orcid.org/0000-0003-3304757X>. E-mail: claudecir.santos@uffs.edu.br

${ }^{2}$ Secretaria Municipal de Educação (SME), Abelardo Luz - SC - Brasil. Professora da rede municipal de ensino do município de Abelardo Luz. Mestre em Educação. ORCID <https://orcid.org/0000-0003-48673821>. E-mail: marciani_maciel@hotmail.com
} 
emphasizes that many teachers are unaware pedagogical training techniques and methods due to unresolved epistemological understandings during his initial training (first degree).

KEYWORDS: PNAIC. Epistemology. Teacher training.

\section{Introdução}

É possível um Programa de formação continuada para professores revelar as insuficiências de uma formação inicial? Uma pesquisa feita no e com o Pacto Nacional pela Alfabetização na Idade Certa (PNAIC) em um município de Santa Catarina, demonstrou haver incompreensões por parte dos professores quanto à relação entre saberes cientificamente produzidos, objetos de ensino e objetos sociais de referência (no caso a educação básica) aos quais os saberes se aplicam.

Apesar das revelações, não temos a pretensão de afirmar que toda formação docente brasileira, sobretudo a formação inicial - primeira Licenciatura - é insuficiente para a constituição de um profissional da educação a altura das demandas de nosso tempo. Porém, após acompanhar, supervisionar e pesquisar, ao longo de três anos, a formação continuada de um grupo de alfabetizadores da rede municipal de ensino do município de Abelardo Luz (SC), chegamos ao entendimento de que é preciso discutir de forma urgente sobre as compreensões/incompreensões epistemológicas produzidas/ reproduzidas nos processos de formação docente.

É com esta intenção que o presente artigo, ao tomar como objeto de investigação relatos de professores alfabetizadores que participaram do PNAIC, procura mostrar que muitos professores desconhecem técnicas e processos de formação pedagógica por conta de (in) compreensões epistemológicas não resolvidas durante sua formação inicial.

Fundamentado na epistemologia de Thomas Kuhn, em especial nas suas reflexões sobre as comunidades científicas e seus representantes, o artigo apresenta dois quadros com relatos dos professores acerca de suas avaliações do PNAIC. Os relatos são baseados em duas Categorias de Análise exploradas na pesquisa: Conteúdo e Sequência Didática.

$\mathrm{O}$ artigo está organizado em dois capítulos. O primeiro: Epistemologia: entre caminhos que se cruzam e cruzamentos que se afastam, apresenta algumas reflexões sobre a epistemologia, fazendo referência às contribuições de Thomas Kuhn. O segundo: Revelações do PNAIC dá voz a relatos de professores participantes do PNAIC que ajudam a problematizar o tema em discussão.

RIAEE - Revista Ibero-Americana de Estudos em Educação, Araraquara, v. esp. n. 3, p. 2071-2086, dez., 2018. E-ISSN: $1982-5587$. 
Nas considerações finais o artigo destaca que precisamos falar de epistemologia quando tratamos da formação e professores, entretanto, ao fazer isso, para além de estudos acerca da história das tendências epistemológicas, precisamos olhar às matrizes curriculares dos cursos de licenciaturas, para os currículos dos professores formadores, e perceber as relações de ambos acerca da formação de futuros professores.

\section{Epistemologia: entre caminhos que se cruzam e cruzamentos que se afastam}

O conheci mento científico, como a linguagem, é intrinsecamente a propriedade comum de um grupo ou então não é nada. Para entendê-lo, precisamos conhecer as características essenciais dos grupos que o criam e o utilizam.

(THOMAS KUHN)

Quem já desenvolveu algum tipo de estudo sobre a epistemologia, ou simplesmente ouviu falar desse conceito, possivelmente, ficou sabendo que ao tratar da epistemologia, em termos gerais, ocupou-se do discurso sobre a ciência e das reflexões sobre as etapas e limites do conhecimento humano.

Mas isso ainda diz pouco sobre a epistemologia. Isso porque, quando apresentada como uma teoria do conhecimento que 'acolhe' postulados, conclusões e métodos dos diferentes ramos do saber científico, a epistemologia se anuncia como um "estudo crítico dos princípios, das hipóteses e dos resultados das diversas ciências" (LALANDE, 1993, p. 313). Contudo, a ciência que dela se faz objeto é a ciência moderna, o que implica em admitir que, sobretudo em função das inúmeras descobertas e mudanças técnico-científicas que aconteceram na era moderna, à epistemologia cabe o papel de perceber as forças advindas de diferentes áreas e fóruns científicos que emergiram com a modernidade.

De todo modo, por abarcar um conjunto amplo de questões, a epistemologia continua sendo uma espécie de filosofia das ciências. Afinal de contas, ela compreende "desde a gênese da ciência, passando pelo seu desenvolvimento, sua estrutura e articulação, seus princípios norteadores, sua racionalidade, seus limites, sua demarcação, seus problemas" (FÁVERO, 2005, p. 55).

Em função dessa realidade emerge certo 'consenso explicativo' em relação ao campo de investigação da epistemologia. Porém, se por um lado tal 'consenso' contribui para o desenvolvimento de estudos e pesquisas, por permitir que o/a pesquisador/a detenha-se em seu objeto de análise a partir do que já está 'acordado', por outro, quando 
não se faz suficiente para a compreensão e explicação dos caminhos da ciência, passa a afetar a investigação científica. Por quê? Porque as etapas e limites do conhecimento humano são movimentos dialéticos que estabelecem ligações com o horizonte epistemológico. Dessa conexão nascem compreensões/incompreensões epistemológicas.

Nesse contexto, ao optarmos pelo termo (in) compreensão, nosso objetivo é dizer que a interiorização de algumas compreensões epistemológicas em certos momentos e espaços, pode, em outros, representar incompreensões. Assim, no caso desse artigo, ao antecipar a palavra compreensão, o prefixo in tem a pretensão de indicar privação e/ou a negação, dai a expressão (in) compreensões epistemológicas...

A epistemologia da qual falamos é a que observa a ciência moderna. Dessa forma, pode-se dizer que, enquanto um discurso sobre a ciência, "a epistemologia é um campo recente do conhecimento, pois é resultado do próprio processo de desenvolvimento da ciência” (FÁVERO, 2005, p. 55). Nessas condições, é “compreensível” que em seu aperfeiçoamento muitos equívocos ainda ocorram, mas isso não dispensa atenção, pois as confusões acerca dos domínios e limites da epistemologia podem mascarar informações que se conjugam e se expressam com o intuito de se transformarem em conhecimentos científicos.

Quando a epistemologia não consegue ser crítica acerca dos princípios, hipóteses e resultados das diversas ciências, ficando deles dependente, mesmo que seja parcialmente, não é apenas o conhecimento científico que se torna duvidoso, mas, também, seu "lugar" vira um campo de disputa por novas 'verdades'.

E quem são aqueles e aquelas que 'reivindicam propriedade' sobre o conhecimento científico? Thomas Kuhn³, no Posfácio da obra: “A Estrutura das Revoluções Científicas”, explica que quem participa de uma comunidade científica, partilha de um conjunto de 'técnicas necessárias' à existência dessa comunidade e, por consequência, tornam legítimas as filiações comunitárias que dai decorrem. São essas pessoas (os membros) e as

3 Thomas Kuhn, a partir de alguns conceitos e reflexões sobre: paradigma; paradigma tradicional; paradigma dominante (crises paradigmáticas/anomalias no paradigma dominante); mudanças paradigmáticas; ciência normal; revolução científica, incomensurabilidade etc., fez um resgate da história da ciência através de seus estudos sobre a "Estrutura das Revoluções Científicas" (obra publicada em 1962). Para Kuhn, a revolução da ciência é um processo não cumulativo, ou seja, concepções são substituídas. Por essas e outras defesas em relação ao desenvolvimento do conhecimento científico, Kuhn se associa a uma concepção histórica de epistemologia, que alguns estudiosos do tema, como Bombassaro, classificam como: nova filosofia da ciência que se desenvolveu na segunda metade do século XX. Mais sobre isso em: BOMBASSARO, Luiz Carlos. As fronteiras da Epistemologia: como se produz o conhecimento. Petrópolis: Vozes, 1992. 
instituições (comunidades científicas) que reivindicam "propriedade" sobre o conhecimento.

E como se forma uma comunidade científica? Sobre isso, Kuhn diz que,

Uma comunidade científica é formada pelos praticantes de uma especialidade científica. Estes foram submetidos a uma iniciação profissional e a uma educação similares, numa extensão sem paralelos na maioria das outras disciplinas. Neste processo absorveram a mesma literatura técnica e dela retiraram muitas das mesmas lições (1998, p. 220).

De acordo com Kuhn, ao se aterem numa mesma literatura técnica e, em grande medida, padronizada, além de marcar os limites de um objeto de estudo científico, os membros de uma comunidade científica garantem para si um objeto de estudo próprio. Com isso, segundo Kuhn, “veem a si próprios e são vistos pelos outros como os únicos responsáveis pela perseguição de um conjunto de objetivos comuns, que incluem o treino de seus sucessores" (KUHN, 1998, p. 221).

É a partir desse contexto que procuramos compreender a formação docente de nossa época. Ou seja, tendo como objeto de estudo o PNAIC, levantamos algumas problematizações acerca de (in) compreensões epistemológicas não resolvidas durante a formação inicial (primeira Licenciatura), procurando enfatizar a necessidade da continuidade de estudos voltados a essa temática.

Diante de tais (in) compreensões, perguntamos: de quem é a culpa? Dos/as graduandos/as que não levaram a sério o Curso de Licenciatura? Dos professores formadores que não prepararam bem seus sucessores? Das Licenciaturas e suas matrizes curriculares, possivelmente, desatualizadas? Das formações apressadas? Da desvalorização dos governantes para com a educação?

Querendo, poderíamos elencar muitos outros motivos além destes, mas não vamos nos estender, pois aqui já temos um conjunto de questões que nos ajudam a pensar sobre algumas das razões pelas quais os professores justificam a aprendizagem, ou a não aprendizagem de seus estudantes.

Frente ao exposto, vale destacar que ao considerarmos a epistemologia como resultado de caminhos que se cruzam entre cruzamentos que se afastam, nossa intenção é discutir sobre os 'saltos da ciência' na modernidade e o controle que seres humanos, de forma individual ou através de instituições, lhes impõe. 
$\mathrm{Na}$ condição de 'propriedade' de alguém, a ciência, assim como o discurso sobre ela, até pode ter aproximado/cruzado caminhos e explicações, mas como são diversas as áreas do saber e múltiplas as perspectivas para descobertas científicas, os cruzamentos, a princípio com a função de juntar caminhos, podem ter provocado efeito contrário. É nesse contexto que enxergamos a epistemologia na contemporaneidade. Ou seja, ao mesmo tempo em que visualizamos suas contribuições para o desenvolvimento da ciência, percebemos emergir (in) compreensões acerca das suas possibilidades e potencialidades para a explicação do conhecimento humano. Sobre essa última condição, a reflexão segue a partir do estudo realizado no e sobre o PNAIC.

\section{Revelações do PNAIC}

O Pacto Nacional pela Alfabetização na Idade Certa (PNAIC) foi criado a partir da Portaria $\mathrm{n}^{\circ} 867$, de 4 de julho de $2012^{4}$. De acordo com o Art. $5^{\circ}$ da Portaria, as ações do Pacto têm por objetivos:

I - garantir que todos os estudantes dos sistemas públicos de ensino estejam alfabetizados, em Língua Portuguesa e em Matemática, até o final do $3^{\circ}$ ano do ensino fundamental;

II - reduzir a distorção idade-série na Educação Básica;

III - melhorar o Índice de Desenvolvimento da Educação Básica (IDEB);

IV- contribuir para o aperfeiçoamento da formação dos professores alfabetizadores;

V - construir propostas para a definição dos direitos de aprendizagem e desenvolvimento das crianças nos três primeiros anos do ensino fundamental (BRASIL, 2012, p. 23).

Foi sob essas, entre outras orientações, que o PNAIC teve início na rede municipal de ensino do município de Abelardo Luz (SC). Implantado em 2013, o PNAIC, embora hoje com outra estrutura, continua sendo um Programa ativo voltado à alfabetização, mas os relatos de experiência que se tornaram objeto da pesquisa em questão dizem respeito aos anos de 2014, 2015 e 2016.

Em 2016 realizamos um levantamento junto à Secretaria Municipal de Educação do município de Abelardo Luz referente aos professores da rede pública municipal de ensino que estavam inseridos no programa.

\footnotetext{
${ }^{4}$ Essa Portaria foi revogada pela Portaria 826/2017/MEC.
}

RIAEE - Revista Ibero-Americana de Estudos em Educação, Araraquara, v. esp. n. 3, p. 2071-2086, dez., 2018. E-ISSN: 1982-5587. 
De posse da informação acerca do número de professores participantes do PNAIC nos anos de 2014, 2015 e 2016, fomos à busca dos seus relatos quanto à avaliação do Programa. Esses relatos se transformaram em objeto de pesquisa. É sobre eles que passamos a debater para avançarmos nas reflexões sobre a formação docente e as (in) compreensões epistemológicas.

O PNAIC contou com a participação de $100 \%$ dos alfabetizadores do município. Destes, nosso recorte se deu na análise dos relatos dos alfabetizadores residentes na zona urbana do município, sendo no total 15 alfabetizadores. Em relação a sua formação acadêmica, dos 15 professores, apenas 2 possuem somente Graduação, os demais (13), tem Especialização Lato Sensu.

Durante a formação os alfabetizadores tomavam nota de possíveis transformações que sua ação docente viesse a sofrer. De forma simples e objetiva, descreviam sua prática pedagógica anterior, durante e após o PNAIC, tendo como apontamentos basilares: os conteúdos trabalhados; as sequências didáticas como ferramenta pedagógica; os direitos de aprendizagem; a autonomia atribuída ao professor alfabetizador; e a metodologia utilizada pelos alfabetizadores. Tais aspectos se transformaram nas Categorias de Análise exploradas na pesquisa.

Infelizmente, nesse espaço, não se faz possível apresentar os relatos referente às cinco categorias citadas. Infelizmente, porque nossas conclusões acerca das (in) compreensões epistemológicas consideraram o conjunto dos relatos. De todo modo, em nosso entendimento, mesmo apresentando os relatos de apenas duas dessas categorias: Conteúdo e Sequência Didática, o artigo consegue ir ao encontro dos objetivos e resultados da pesquisa.

\section{Categoria 1 - Conteúdo}

Não podemos falar de conteúdo sem lembrarmos o conhecimento, ambos estão intimamente ligados, dificilmente um acontece sem o outro. Para o PNAIC, os conteúdos não são prontos e acabados, desconexos com a realidade do educando, os conteúdos carregam a missão da promoção do conhecimento nas mais diversas áreas. 
A socialização do conhecimento acontece por meio dos conteúdos que perpassam a sala de aula. Os documentos oficiais do PNAIC (a exemplo do Caderno I - Unidade 6) ${ }^{5}$ expressam o posicionamento do programa frente aos conteúdos, reforçando que tomar decisões acerca dos conteúdos a serem trabalhos é, sem dúvida, algo complexo e desafiador (BRASIL, 2012).

A escolha de conteúdos, porém, não é algo simples de se fazer. Perrenoud ${ }^{6}$ (2002) acredita que o professor, por mais comprometido que venha a ser, nem sempre consegue observar sua caminhada. Muitas vezes, ele é guiado por ações irrefletidas e pelo próprio movimento do seu dia a dia, que o fazem agir impulsivamente dentro de uma rotina préestabelecida. Entretanto, é sabido que relembrar e refletir sobre o próprio caminho percorrido pode ser revelador de práticas que precisam ser superadas, reconstruídas e/ou modificadas. É justamente em meio a estas fragilidades que o programa do PNAIC propõe a discussão, a diagnose e a reflexão acerca dos conteúdos e métodos utilizados.

Mas quais conteúdos devem ser priorizados e ensinados? Para Perrenoud (2002), refletir sobre essa pergunta implica em debater sobre a reconstrução do objeto implicando na passagem de saberes cientificamente produzidos ou de práticas socialmente realizadas para os objetos ou práticas a ensinar. Nesse sentido, ao selecionar conteúdos a serem ensinados, é imprescindível uma vigilância para que seja evitado um distanciamento entre o objeto de ensino e o objeto social de referência, bem como pensar-se numa hierarquização, o que deve ser considerado prioritário ou enfatizado no âmbito do objeto de ensino (BRASIL, 2012).

Frente a isso, considerando o que diziam os relatos, e, problematizando-os à luz da epistemologia de Thomas Kuhn, passamos a perguntar: os membros (professores formadores) de uma comunidade científica estão conseguindo explicar as imbricações entre os saberes cientificamente produzidos, objetos de ensino e objeto social de referência? Vejamos alguns relatos para em seguida voltarmos a essa questão.

5 Disponível em: http://pacto.mec.gov.br/materiais-listagem/item/61-caderno-6-a-arte-no-ciclo-dealfabetizacao. Acesso em: 10 mar. 2018.

${ }^{6}$ Philippe Perrenoud é doutor em Sociologia e Antropologia e atua nas áreas relacionadas com o currículo, práticas pedagógicas e instituições de formação nas faculdades de Psicologia e de Ciências da Educação da Universidade de Genebra. 
Quadro 1 - Conteúdo

\begin{tabular}{|c|c|c|}
\hline Alfabetizador & Antes & Depois \\
\hline $\mathrm{RA}^{7}$ & "conteúdos prontos e acabados" & $\begin{array}{l}\text { "coisas reais que fazem sentido e que } \\
\text { tem significado para o educando" }\end{array}$ \\
\hline RA2 & $\begin{array}{l}\text { "não se tinha uma visão ampla de } \\
\text { como introduzir os conteúdos" }\end{array}$ & \\
\hline RA3 & $\begin{array}{l}\text { "desde que iniciei venho participando } \\
\text { do PNAIC, desde então sempre me } \\
\text { organizei usando sequência didática, } \\
\text { isso me fez organizar melhor os } \\
\text { conteúdos a serem trabalhados" }\end{array}$ & $\begin{array}{l}\text { "agora as crianças fazem ligação com } \\
\text { os conteúdos" }\end{array}$ \\
\hline RA4 & $\begin{array}{l}\text { "antes do PNAIC trabalhava } \\
\text { disciplinas isoladas" }\end{array}$ & $\begin{array}{l}\text { "hoje realizo as atividades interligadas } \\
\text { com as disciplinas oferecidas pela } \\
\text { proposta municipal, porém, há um } \\
\text { maior significado ao repassar e } \\
\text { apresentar os conteúdos" }\end{array}$ \\
\hline RA5 & & $\begin{array}{l}\text { "Vimos que as Sequências didáticas } \\
\text { abrem grandes possibilidades de } \\
\text { realizar trabalhos interdisciplinares, } \\
\text { articulando os conteúdos de maneira } \\
\text { objetiva relacionando as vivências dos } \\
\text { alunos permitindo maior compreensão" }\end{array}$ \\
\hline RA6 & & $\begin{array}{l}\text { "Seleção e discussão de temáticas } \\
\text { fundantes em cada área de } \\
\text { conhecimento" }\end{array}$ \\
\hline RA7 & $\begin{array}{l}\text { "O PNAIC (Pacto Nacional pela } \\
\text { Alfabetização na Idade Certa) veio } \\
\text { para fazer os professores } \\
\text { alfabetizadores refletirem sobre o } \\
\text { currículo e as ações nos anos iniciais } \\
\text { do ensino fundamental" }\end{array}$ & $\begin{array}{l}\text { "Definiu direitos de aprendizagem e } \\
\text { desenvolveu nas áreas de leitura e } \\
\text { escrita, matemática" }\end{array}$ \\
\hline RA8 & & $\begin{array}{l}\text { "Com a formação do PNAIC chamou } \\
\text { atenção para tudo àquilo que a só a } \\
\text { Escola ensina, como por exemplo: } \\
\text { Calendários, horas, mapas" }\end{array}$ \\
\hline RA9 & & $\begin{array}{l}\text { "A formação tem influência do muito o } \\
\text { ensino em sala de aula" }\end{array}$ \\
\hline RA10 & & $\begin{array}{l}\text { "Claramente evidenciou a necessidade } \\
\text { de oportunizar aos alunos o contato } \\
\text { direto com os diferentes gêneros } \\
\text { textuais" }\end{array}$ \\
\hline RA11 & $\begin{array}{l}\text { "Realidade de ensino diferente a qual } \\
\text { eu estava acostuma" }\end{array}$ & $\begin{array}{l}\text { "O trabalho abrange as áreas da } \\
\text { alfabetização matemática" }\end{array}$ \\
\hline RA12 & & $\begin{array}{l}\text { "a formação trouxe algumas reflexões } \\
\text { sobre a alfabetização e isso refletiu em } \\
\text { nossa prática" }\end{array}$ \\
\hline RA13 & $\begin{array}{l}\text { "O curso do PNAIC trouxe } \\
\text { conhecimentos como trabalhar e o que } \\
\text { trabalhar com os educandos" }\end{array}$ & $\begin{array}{l}\text { "Contribuiu para que pudéssemos } \\
\text { seguir um roteiro de conteúdos } \\
\text { condizentes com a realidade de nossos } \\
\text { educandos e dos direitos de } \\
\text { aprendizagem" }\end{array}$ \\
\hline
\end{tabular}

${ }^{7}$ RA $=$ Relator Alfabetizador 


\begin{tabular}{|l|l|l|}
\hline \multirow{2}{*}{ RA14 } & & $\begin{array}{l}\text { "A formação nos leva a olhar para as } \\
\text { individualidades existentes na sala, } \\
\text { respeitando a forma de aprender e o } \\
\text { tempo necessário para que o } \\
\text { aprendizado aconteça" }\end{array}$ \\
\hline \multirow{3}{*}{ RA15 } & $\begin{array}{l}\text { "Antes da formação do PNAIC já se } \\
\text { ouvia falar em letramento e e } \\
\text { alfabetização, porém eram conceitos a formação, os estudos e } \\
\text { compreendidos de forma restrita e até } \\
\text { mesmo um pouco confusa" }\end{array}$ & $\begin{array}{l}\text { reflexões, conseguimos compreender os } \\
\text { conceitos, e refletirmos em torno do } \\
\text { planejamento, dos currículos, dando } \\
\text { qualidade ao trabalho dos educadores" }\end{array}$ \\
\hline
\end{tabular}

Fonte: elaboração dos autores (2017)

De acordo com o quadro acima, nos relatos RA1, 2, 3,4,5 e 6, os conteúdos agora não são mais prontos e acabados, passando a fazer sentido para os alunos, sendo possível relacionálos. O relato RA8 menciona saberes que só a escola contempla. RA9 fala das influências na prática pedagógica a partir do programa. RA10 ressalta o contato com os diferentes gêneros textuais que a formação trouxe para sala de aula. Conforme RA11, o trabalho passou a abrangera alfabetização matemática de forma inovadora. Já o relato RA12 traz as reflexões sobre a prática.

Alguns relatos dizem ainda que roteiros de conteúdos condizentes com a realidade dos educandos e dos direitos de aprendizagem contribuíram para o alcance dos objetivos RA13. No parecer do RA14, o alfabetizador reforça o respeito a individualidade. Por fim, para o relato RA15, os conceitos de alfabetização e letramento, apesar de conhecidos, não eram compreendidos; através do estudo, de reflexões, conceitos foram assimilados, qualificando assim o trabalho dos educadores.

Os relatos sobre a categoria Conteúdo suscitaram importantes debates, conclusões e hipóteses. Voltaremos a essas suscitações no último parágrafo desse capítulo e nas considerações finais.

\section{Categoria 2 - Sequência Didática}

Sequência didática é um termo utilizado na educação para definir um procedimento desencadeado por vários passos, ou etapas, ligadas entre si para tornar mais eficiente o processo de aprendizado. As sequências didáticas podem ser definidas como conjunto de atividades ligadas entre si, planejadas para ensinar um determinado conteúdo de escolha do professor, etapa por etapa. As sequências didáticas são organizadas de acordo com os objetivos 
que o professor quer alcançar para a aprendizagem de seus alunos, envolvendo atividades diversas de aprendizagem.

O termo Sequência Didática surgiu em 1996, na França, a partir da necessidade de superação da compartimentalização dos conhecimentos no campo das linguagens. Uma sequência didática, de acordo com Dolz e Schneuwly (2004), possibilita a criação de contextos de produção promovendo atividades das mais variadas, a fim de que o aluno domine determinado gênero em situações de comunicação das mais diversas. Para Dolz e Schneuwly "elas procuram favorecer a mudança e a promoção dos alunos ao domínio dos gêneros e das situações de comunicação" (DOLZ; SCHNEUWLY, 2004, p. 53).

Segundo os autores, as sequências didáticas devem compreender um conjunto de atividades planejadas, sistemática, em torno de um gênero textual. Apesar de as sequências didáticas inicialmente contemplarem o estudo das linguagens, no PNAIC as sequências ganham um novo formato, abordando não só a alfabetização matemática, mas também a interdisciplinaridade.

Embora não seja nenhuma novidade, no caso da educação municipal de Abelardo Luz, a sequência didática chegou à Escola com o Programa do PNAIC (dai uma das motivações para dar continuidade ao debate sobre a formação inicial de professores). A partir desse momento, com a metodologia de trabalho do PNAIC, os professores alfabetizadores, com base em um gênero textual, passaram a elaborar sua sequência didática, escolhendo os conteúdos de acordo com seus objetivos.

No quadro abaixo podemos perceber como os professores alfabetizadores encaram o trabalho com as sequências didáticas.

Quadro 2 - Sequência Didática

\begin{tabular}{|c|c|c|}
\hline $\begin{array}{l}\text { Alfab } \\
\text { etizador }\end{array}$ & Antes & Depois \\
\hline RA1 & & $\begin{array}{l}\text { "Considero minha prática muito mais } \\
\text { qualificada depois do PNAIC. Através } \\
\text { das Sequências Didáticas consigo } \\
\text { observar e diagnosticar melhor as } \\
\text { dificuldades" }\end{array}$ \\
\hline RA2 & $\begin{array}{l}\text { "Antes do PNAIC, nós alfabetizadores } \\
\text { trabalhávamos com projetos, não } \\
\text { tínhamos outra visão sobre como } \\
\text { introduzir dos conhecimentos" }\end{array}$ & $\begin{array}{l}\text { "É possível perceber uma } \\
\text { transformação na minha prática em sala } \\
\text { de aula, nos resultados dos trabalhos, } \\
\text { através do desenvolvimento das } \\
\text { sequências didáticas" }\end{array}$ \\
\hline RA3 & & $\begin{array}{l}\text { "A sequência didática abrange a } \\
\text { interdisciplinaridade em sala fazendo } \\
\text { com que as crianças façam ligação entre } \\
\text { os conteúdos" }\end{array}$ \\
\hline RA4 & "Eu não participava do PNAIC, eu & "Hoje estou trabalhando com sequência \\
\hline
\end{tabular}




\begin{tabular}{|c|c|c|}
\hline & $\begin{array}{l}\text { apenas observava, duas professoras } \\
\text { que participavam, realizando } \\
\text { atividades de sequência didática, tive } \\
\text { interesse" }\end{array}$ & $\begin{array}{l}\text { didática, que contribui na organização } \\
\text { do planejamento, buscando atender } \\
\text { todos os níveis, tornando o processo de } \\
\text { ensino-aprendizagem mais eficaz e de } \\
\text { qualidade" }\end{array}$ \\
\hline RA5 & & $\begin{array}{l}\text { "Visto que com as sequências didáticas } \\
\text { abre grandes possibilidades de realizar } \\
\text { trabalhos interdisciplinares, facilitando } \\
\text { o desenvolvimento das atividades" }\end{array}$ \\
\hline RA6 & & $\begin{array}{l}\text { "Há integração entre os componentes } \\
\text { curriculares" }\end{array}$ \\
\hline RA7 & & $\begin{array}{l}\text { "O trabalho com sequência didática } \\
\text { favoreceu a busca e o uso de novas } \\
\text { tecnologias onde as atividades lúdicas } \\
\text { facilitam aprendizagem" }\end{array}$ \\
\hline RA8 & & $\begin{array}{l}\text { "Hoje trabalho apenas com sequência } \\
\text { didática, a cada gênero estudado para } \\
\text { cada sequência é uma experiência nova } \\
\text { e é um objetivo alcançado, o que torna a } \\
\text { aula mais produtiva e a alfabetização } \\
\text { cheia de magia" }\end{array}$ \\
\hline RA9 & $\begin{array}{l}\text { "Eu tive resistência em trabalhar com } \\
\text { sequência didática, o novo assusta, me } \\
\text { sentia confortável no que eu já sabia" }\end{array}$ & $\begin{array}{l}\text { "A partir do momento que fui } \\
\text { conhecendo do que se tratava às } \\
\text { sequências didáticas, adorei trabalhar, e } \\
\text { percebi com meus alunos gostaram e } \\
\text { interagem bem mais" }\end{array}$ \\
\hline RA10 & & $\begin{array}{l}\text { "Um aspecto que me chamou atenção é } \\
\text { o de que o ensino das linguagens deve } \\
\text { partir do gênero textual" }\end{array}$ \\
\hline RA11 & $\begin{array}{l}\text { "Iniciei o trabalho com sequência } \\
\text { didática, no começo parecia } \\
\text { complicado, até mesmo pela forma que } \\
\text { estava acostumada a trabalhar" }\end{array}$ & $\begin{array}{l}\text { "A partir de então pude perceber e } \\
\text { compreender que os alunos podem } \\
\text { aprender de diferentes maneiras, } \\
\text { principalmente de forma lúdica, e } \\
\text { conseguindo um trabalho que abrange a } \\
\text { alfabetização matemática" }\end{array}$ \\
\hline RA12 & & $\begin{array}{l}\text { "Com a sistematização do } \\
\text { conhecimento organizamos nossas } \\
\text { rotinas em forma de sequência didáticas } \\
\text { interdisciplinares, priorizando a } \\
\text { ludicidade necessária a idade dos } \\
\text { alfabetizando" }\end{array}$ \\
\hline RA13 & Não abordado & Não abordado \\
\hline RA14 & & $\begin{array}{l}\text { "as sequências melhoram o trabalho, } \\
\text { com diversidade, sendo uma aula mais } \\
\text { prazerosa" }\end{array}$ \\
\hline RA15 & Não abordado & Não abordado \\
\hline
\end{tabular}

Fonte: elaboração dos autores (2017)

No quadro 2 percebemos que os RA1, 2, 4,8 e 9 consideram o trabalho com as Sequências Didáticas eficaz. Segundo os depoimentos, a Sequência Didática transformou a ação docente, qualificando o trabalho. Sobre a interdisciplinaridade permitida e incentivada 
a partir das sequências, os relatos RA3, 5, 6,12 e 14 assumem um posicionamento positivo sobre tal metodologia de trabalho, apontando a integração dos conteúdos como melhoria da prática educativa. Os RA7 e 11 ressaltam que a tecnologia que foi aliada à sequência e à ação docente facilita o processo de ensino-aprendizagem. Os relatos RA13 e RA15 não manifestaram parecer sobre as Sequências Didáticas.

Em síntese, podemos dizer que do conjunto dos relatos emergiram conclusões e hipóteses merecedoras de releituras e problematizações acerca do que pensam os professores sobre as concepções epistemológicas que fundamentam seus processos de formação e avaliação de suas práticas. Mas é preciso relembrar que o conjunto dos relatos compreende as cinco categorias analisadas e, nesse artigo, apenas duas foram apresentadas. Considerando isso, achamos por bem dar destaque a conclusões e hipóteses que fizeram eco as categorias: Conteúdo e Sequência Didática.

Quanto às conclusões, podemos apontar duas: a) apesar dos professores possuírem alicerces teóricos, metodológicos e jurídicos para chegarem à sala de aula, estes se mostram insuficientes (e talvez nunca sejam suficientes) para a compreensão das epistemologias que envolvem o fazer docente. Nesse caso, é preciso diminuir as lacunas entre concepções epistemológicas, realidade da sala de aula e processos de alfabetização; b) o PNAIC foi acolhido por muitos professores como o programa que resolveria os problemas da alfabetização, e quem assim o fez, frustrou-se, pois não se resolve problemas que apresentam origens epistêmicas, sociais e culturais com programas de 'treinamento' o PNAIC, obviamente, não foi estruturado para ser um programa de treinamento, mas muitos o entenderam como tal -. Quanto às hipóteses, vale destacar nossa desconfiança em relação as matrizes curriculares dos cursos de licenciatura, em particular o curso de Pedagogia. Ou seja, nossa hipótese é de que, em grande medida, as insuficiências na formação inicial dos alfabetizadores estão nas matrizes curriculares dos cursos de Pedagogia. Em particular no 'inchaço’ de ementas curriculares que, apesar de longas, não relacionam: concepções epistemológicas, realidade da sala de aula e processos de alfabetização. Essa hipótese, porém, merece explicações que esse artigo não possibilita, por isso, em outra oportunidade voltaremos a ela.

\section{Considerações finais}


Em relação às questões que elencamos sobre: de quem seria a culpa diante das (in) compreensões epistemológicas? A partir da pesquisa realizada, nossa resposta é: de algum modo, todos/as os/as citados naquelas questões possuem suas parcelas de culpa, entretanto, considerando o que presenciamos no PNAIC, somos levados a concordar com Thomas Kuhn e suas afirmações quanto à postura das comunidades científicas e suas práticas esotéricas. No entendimento de Kuhn, quando acontece uma transição de um paradigma a outro, ou seja, uma mudança de modelo, estrutura, comportamento etc., os novos quebracabeças para resolver problemas trazem consigo uma complexidade que nem todos/as estão aptos/as a administrar. $\mathrm{E}$ isso parece acontecer nos processos de formação dos professores brasileiros. O que não significa dizer que os processos são falhos em sua integralidade, significa dizer que são perfectíveis.

Nossas conclusões, fundamentadas na pesquisa acerca do PNAIC em Abelardo Luz, em primeiro lugar, apontam para o óbvio: o conhecimento científico é produzido por pessoas e defendido conforme suas compreensões e convicções do que seja melhor para o desenvolvimento da humanidade. Assim, conforme expressa a epígrafe inicial, "para entendê-lo, precisamos conhecer as características essenciais dos grupos que o criam e o utilizam" (KUHN, 1998, p. 257). Em segundo lugar, aventa uma proposta de formação docente em que os profissionais da educação consigam permanecer, diuturnamente, críticos em relação ao 'movimento' dos princípios, das hipóteses e dos resultados das diversas ciências contemporâneas.

Nesse sentido, às referências a Kuhn, mais do que fundamentar o que seja a epistemologia, servem para destacar a influência das comunidades científicas, seus membros e modelos de formação acadêmica da qual fizeram parte diferentes gerações de professores. Pois, se partirmos do pressuposto de que enquanto filosofia das ciências a epistemologia se desenvolveu com e a partir da modernidade, logo, podemos concluir que as gerações de professores que 'fizeram' a escola que temos hoje, direta ou indiretamente, foram influenciadas pelas tendências ${ }^{8}$ epistemológicas que emergiram nesse período.

Portanto, precisamos falar de epistemologia quando tratamos da formação e professores, O PNAIC revelou insuficiências na formação inicial de professores que precisam ser discutidas à luz da epistemologia, mas mais do que se ater a um estudo histórico das tendências epistemológicas, precisamos olhar às matrizes curriculares dos

8 Em relação às Tendências da Epistemologia, ver: JAPIASSÚ, Hilton. Introdução ao pensamento epistemológico. 7 ed. Rio de Janeiro: Francisco Alves, 1992. E, BOMBASSARO, Luiz Carlos. As fronteiras da Epistemologia: como se produz o conhecimento. Petrópolis: Vozes, 1992.

RIAEE - Revista Ibero-Americana de Estudos em Educação, Araraquara, v. esp. n. 3, p. 2071-2086, dez., 2018. E-ISSN: $1982-5587$. 
cursos de licenciaturas, aos currículos dos professores formadores e ao entendimento e relações de ambos acerca da formação de futuros professores.

\section{REFERÊNCIAS}

BARDIN, Laurence. Análise de conteúdo. Edição revista ampliada, $3^{\mathrm{a}}$ reimpressão da $1^{\mathrm{a}}$ edição. Lisboa: Edições 70, 2014.

BRASIL. Ministério da Educação. Portaria no - 867, de 4 de julho de 2012. Brasília: Diário Oficial da União - Seção 1, n. 129, p. 23, quinta-feira, 5 de julho de 2012.

BRASIL. Secretaria de Educação Básica. Diretoria de Apoio à Gestão Educacional. Pacto Nacional pela Alfabetização na Idade Certa. A arte no ciclo de alfabetização. Caderno 06. Ministério da Educação, Secretaria de Educação Básica, Diretoria de Apoio à Gestão Educacional. - Brasília: MEC, SEB, 2015.

BRASIL. Secretaria de Educação Básica. Diretoria de Apoio à Gestão Educacional. Pacto Nacional pela Alfabetização na Idade Certa: formação do professor alfabetizador.

Caderno de apresentação. Brasília: MEC; SEB, 2012.

DOLZ, Joaquin.; SCHNEUWLY, Bernard. Gêneros e progressão em expressão oral e escrita: elementos para reflexões sobre uma experiência suíça. In: SCHNEUWLY, B.; DOLZ, J. Gêneros orais e escritos na escola. Campinas: Mercado de Letras, 2004.

FÁVERO, Altair Alberto. As conexões entre epistemologia e filosofia. In: PICLER, Nadir Antonio; TESTA, Edimárcio. Epistemologia, ética e hermenêutica. Passo fundo: Ed. Universidade de Passo Fundo, 2005.

KUHN. Thomas S. A estrutura das revoluções científicas. São Paulo: Editora Perspectiva S. A., 1998.

LALANDE, André. Vocabulário técnico e crítico da filosofia. São Paulo: Martins Fontes, 1993.

PERRENOUD, Philippe. A prática reflexiva no ofício de professor. Porto Alegre: Artmed, 2002.

PERRENOUD, Philippe.; THURLER, Monica Gather. As competências para ensinar no século XXI: a formação dos professores e o desafio da avaliação. Porto Alegre: Artmed, 2002.

PICLER, Nadir Antonio.; TESTA, Edimárcio. Epistemologia, ética e hermenêutica. Passo fundo: Ed. Universidade de Passo Fundo, 2005. 


\section{Como referenciar este artigo}

SANTOS, Claudecir dos.; MACIEL, Marciane. A formação docente e as (in) compreensões epistemológicas. Revista Ibero-Americana de Estudos em Educação, Araraquara, v. esp. n. 3, p. 2071-2086, dez., 2018. E-ISSN: 1982-5587. DOI: 10.21723/riaee.unesp.v13.iesp3.dez.2018.11129.

Submetido em: 28/02/2018

Revisões requeridas: $12 / 04 / 2018$

Aprovado em: 26/07/2018 